\title{
HERMANN WEYL Y ORTEGA \\ Posibles ejes de influencia físico-matemáticos proyectados sobre el entramado conceptual orteguiano acerca de la Ciencia
}

Luis GARCIA AGUILAR

\section{Introducción}

La obra de D. José Ortega y Gasset, como ocurre con todo destacado intelectual, se halla entrecruzada de numerosas aportaciones, influencias, inspiraciones, etc., provenientes de autores y temas muy diversos que, en una u otra medida, colaboran a marcar el rumbo de su pensamiento. Máxime en este caso, por tratarse de un espíritu sumamente receptivo a cuantos acontecimientos configuraban los rasgos más peculiares de su tiempo. La bibliografia sobre nuestro filósofo es abundante en ensayos sobre las influencias que, más o menos explícitas, contribuyen a dar razón de determinados aspectos de su doctrina filosófica ${ }^{1 .}$

En lo sustancial, la exposición aquí emprendida pretende destacar una línea de influencia o inspiración, perceptible en la obra orteguiana. Corriente de ideas inscrita en el pensamiento del matemático y físico alemán Hermann Weyl, que posee innegable proyección, según mi parecer, sobre la reflexión de Ortega acerca de diversos aspectos relacionados con la ciencia y que cristaliza en múltiples lugares de su obra. Se trata de una actividad que gira en torno a subrayar o mostrar, ajena a reclamar papel alguno como "descubridores» de soterrados y hasta ahora desconocidos flujos de influencias. Queda, pues, reducido nuestro intento a iluminar con mayor intensidad esa dimensión de su pensamiento que es la ciencia.

1 Véase nota bibliográfica al final. 
Desarrollaremos este estudio comenzando por una previa exposición —en trazos gruesos- de los elementos clave de la concepción orteguiana acerca del ser o consistencia de la ciencia, exhibiendo a continuación sus textos más directamente relacionados con tal faceta. Inmediatamente dedicaremos una atención preferente a los textos del físico y matemático, donde cabe hallar la fuente de inspiración para ese centro neurálgico de ideas. Realizado el trabajo principal, nuestro interés se desplazará hacia una serie de temas concomitantes, de ubicación más periférica respecto de esta particular noción de la ciencia, donde igualmente se hace patente la asimilación de ideas presentes en el trabajo de Weyl. Son estos, el holismo de las teorías científicas, el indeterminismo, la métrica, a los que se podría sumar algunos nódulos de la teoría del conocimiento. Con el fin de conseguir la mayor eficacia expositiva, parece lo más conveniente cambiar un tanto el método aplicado al tratamiento de estos últimos puntos temáticos. Así, sobre el contenido de cada uno de ellos, nos iremos ocupando de ambas opiniones, la del científico y la del filosofo.

Cabe resaltar que la expresada línea de inspiración originada en Weyl, cuya importancia pretendemos hacer patente, aun hallando eco en las propias citas que Ortega recoge, no llaga a obtener un reconocimiento explícito por el filósofo madrileño, como ocurre con la envergadura concedida a la influencia del biólogo von Uexküll (PPA, VIII, 54) sobre su reflexión en determinada época de su vida; o como las incitaciones suscitadas - como él mismo confiesa- por una cierta actitud ucrónica de la ciencia, ejemplarizada por el fisiólogo Loeb ${ }^{2}$. Las sugestiones recibidas de Weyl, no obstante, se entretejen en la trama de la doctrina orteguiana de la ciencia de una manera definitiva a lo largo de su obra. De ahí que adquieran, en ese ámbito, una importancia de primer orden.

El texto de $\mathrm{H}$. Weyl, único que va a ocupar el foco de nuestra atención, pues aunque también se encuentran referencias de Ortega a otros trabajos suyos, nos parecen carentes de relevancia para el caso, lleva por título "Philosophie der Matehematik und Naturwissenschaft” ${ }^{3}$. Se trata de un artículo, contribución de su autor al Handbuch der Philosophie, de R. Oldenbourg, en 1926, posteriormente ampliado y convertido en libro, vertido al inglés ${ }^{4}$ y cuya versión cas-

2 Cfr. (SHE, III, 239); idea que volverá a reiterar en (HS, VI, 22).

3 Ortega cita explícitamente este trabajo en (FHH, IV, 527, nota), escrito en el año 1927 y publicado a comienzos de 1928, según narra en (BF, V, 284).

4 Philosopby of Mathematics and Natural Sciencie. Princenton University Press, 1949 (4.a reimpresión, 1959. 
tellana hemos utilizado5. Efectúa el matemático alemán, dicho grosso modo, un recorrido a través de los principios de la lógica matemática, de la axiomática; pasando por los fundamentos de la teoría de los números y dispensando una atención muy especial a los problemas implicados en el continuo y en la noción del infinito. Igualmente trata cuestiones geométricas fundamentales, como concepciones no-euclidianas, n-dimensionales, congruencia, similaridad y topología. En la ciencia natural se reduce, principalmente, a la física, atendiendo a diversos aspectos de la problemática del espacio-tiempo; a las implicaciones científicas de la epistemología; a la Metodología; para finalizar con una visión o retrato físico del universo, bajo el prisma de la materia y distintos aspectos de la causalidad. De todo el substancioso entramado conceptual de su exposición, caracterizado aquí de forma tan somera y aun considerándolo de gran interés, sólo nos detendremos, por razones de espacio, en aquellas cuestiones cuya relación con el pensamiento orteguiano nos parezca de interés.

Considero ineludible dejar constancia de unas ciertas reservas sobre la idoneidad de la edición del libro utilizado. Se concreta el asunto a que Ortega dispuso del artículo en cuestión escrito en alemán. Hubiera sido deseable examinar el ejemplar manejado por el filósofo. Sus notas, subrayados u otra clase de signos serían otras tantas claves para seguir el hilo de su reflexión. Mas hay que lamentar que dicho ejemplar se perdiera, por causas atribuibles a las vicisitudes derivadas de nuestra guerra civil. Debido a mi desconocimiento de la lengua alemana me he servido de la versión castellana del libro. Cabe, entonces, preguntarse sobre el grado de adecuación al texto alemán original. De haberse tratado de una labor de crítica textual, centrada en una comparación de los mismos que coloca en primer plano su literalidad, al punto hubiera desistido de mi empeño. Ahora bien, apuntando este trabajo a destacar posibles influencias o elementos inspiradores, es evidente que aquí entramos en un tratamiento más inclinado hacia lo conceptual, más allá de hipotéticas diferencias surgidas en la traslación idiomática. Igualmente surge la duda acerca de supuestas interferencias que las ampliaciones llevadas a cabo hubieran podido producir. Mas del titubeo inicial sobre este punto nos ha disuadido la aclaración que el propio Weyl realiza en el "Prólogo" al libro editado en versión inglesa. Allí nos dice:

5 Filosofia de Las Matemáticas y de la Ciencia Natural. Universidad Nacional Autónoma de México. México, 1965. 
4A pesar de las numerosas alteraciones detalladas - menciono en especial las secciones $13-15$ y la sección 23 final-, se ha preservado la sustancia del texto antiguo." 6

A esta explicitación cabe agregar la corroboración que las citas de Ortega suponen. La fidelidad a las ideas allí expuestas y la levedad de los matices, nos ha parecido garantía suficiente. Hay que añadir que las nociones principales transmigradas al pensamiento orteguiano son tratadas en muy diferentes lugares y con relación a núcleos temáticos diversos, lo cual hace extremadamente improbable que se produzcan desviaciones importantes respecto al artículo original. Pese, pues, a las reservas expresadas, creemos que éstas no afectan significativamente a los contenidos del texto manejado.

\section{Prolegómenos}

Aspectos relevantes de la concepción orteguiana de la ciencia

Obvias razones de espacio nos vedan acometer la exposición de la teoría orteguiana de la ciencia en toda su amplitud. Cabe también señalar que no estamos ante una concepción integral y detallada, al no haber sido Ortega un filósofo de la ciencia. Y sumemos a esto las complejidades y aun dificultades implicadas en la reflexión epistemológica del intelectual español, que nos llevarían demasiado lejos. Así pues, en cierta medida - parcialmente, por tantohemos de dar por conocida la doctrina orteguiana, siquiera sea en sus elementos nucleares. No obstante, parece conveniente ofrecer una visión panorámica de los puntos fundamentales, a fin de configurar el horizonte de la reflexión orteguiana sobre este orbe. En reserva quedan algunas referencias de sus escritos para el posterior tratamiento de otros aspectos, de importancia menor, donde se resaltará con claridad la afinidad estudiada.

Confirman la importancia atribuida por Ortega a la ciencia las referencias a ella en casi todas sus obras de relieve. Sin entrar en mayores matizaciones, cabe afirmar que, desde su perspectiva, el núcleo de la Ciencia queda constituido por las tres ciencias básicas: lógica, matemáticas y física, conformadoras de lo que vino a denominar "la acrópolis, la ciudadela de la inteligencia o razón" (RH44,

6 Op. cit., p. VIII. El subrayado es nuestro. 
XII, 286). Pues bien, aún siendo la ciencia el centro cordial de una Modernidad -en su opinión ya obsoleta - cuya superación entendía como la misión específica de su tiempo, no dirige el filósofo madrileńo contra ella similares embates a los lanzados sobre las restantes corrientes conformadoras de esa edad fundamentada en el idealismo. Actitud que, en líneas muy generales, atestigua el índice del status tan especial que la ciencia asume en su reflexión y donde viene a insertarse, siempre según mi particular opinión, la aludida corriente de ideas que parte de $\mathrm{H}$. Weyl. De otro lado, las probables asunciones de ideas y conclusiones filosóficas manifestadas por Weyl, en nada merman el genio ni la originalidad de Ortega, filósofo a secas, ni tan siquiera filósofo de la ciencia, y menos aún científico, como el mismo Weyl. Al contrario, ejemplifica una actitud encomiable, alerta ante acontecimientos que, sin pertenecer a su propio campo, le aportan una especial dilatación de su horizonte intelectual.

El punto de partida está en la clara conciencia del filósofo madrileño acerca de la crisis de fundamentos que afectaba, cada vez en mayor medida, a aquellas tres ciencias señeras para la compresión del mundo. Conocimiento adquirido por medio de la racionalidad científica, que se había convertido en cuestión de amplísimos debates. La racionalidad subyacente se tornaba pequeña isla sobre océanos de irracionalidad. El conocimiento devenía en algo cada vez más simbólico, proceso cuyo resultado último cristalizaba en el alejamiento de la ciencia como conocimiento de algo real, lo que ocurría paralelamente a un éxito creciente en el campo de su aplicación práctica. El foco central de la concepción orteguiana consiste en caracterizar al conocimiento científico como construcción simbólica. Aunque ambos hilos temáticos - constructivismo y simbolismo- se hallen en numerosas ocasiones entrelazados, a los simples efectos expositivos emprendemos una explicación separada. Al margen tenemos que dejar otro elemento conceptual concomitante, en cierta manera derivado de los anteriores, el instrumentalismo, de no menuda relevancia en Ortega, pero que apenas recibe tratamiento en el libro de Weyl.

Ese núcleo de ideas aparece casi completo en su trabajo «La Filosofia de la Historia de Hegel y la historiologían, elaborado en 1927, fecha extraordinariamente reveladora, pues su lectura de Weyl es todavía reciente. En este ensayo expone con suma claridad el eje de su visión gnoseológica sobre la ciencia. Concepción inspirada por la física, cuya función y estructura - bajo ese prisma y hablando en términos genéricos, sin referirse a los objetos, métodos y contenidos de cada ciencia particular- pretende extender a toda ciencia que tenga por objeto la realidad. Así, nos manifiesta: "Ciencia no significa jamás «empiria», 
observación, dato a posteriori, sino todo lo contrario: construcción a priori." (FHH, IV, 527). Construcción que es obra de la fantasía y muy cercana en parentesco a la poesía. Son relativamente abundantes los pasajes de la obra orteguiana donde aparece esta idea nuclear de que la ciencia es construcción. La presenta con variados matices, perspectivas diversas, incluso en ocasiones equilibrándola de algún modo con la actividad empírica y experimental de la ciencia. No cabe aquí reproducir todos esos textos, que se pueden encontrar, principal pero no únicamente, en trabajos de distinta índole como son ¿Qué es filosofia?, ¿Qué es conocimiento?, Unas lecciones de Metafisica, Ideas y creencias, Historia como sistema, "Bronca en la física", "La razón histórica" (Buenos Aires, 1940), Apuntes sobre el pensamiento. Su teurgia y su demiurgia, y La idea de principio en Leibniz.

Por lo que al componente simbólico respecta, nueva faz que adopta el conocimiento derivado de la construcción teórica de la ciencia, queda muy bien apuntado en las páginas de su trabajo sobre Hegel, donde deja constancia de que entre el sistema de las teorías de la ciencia física y el complejo de hechos observacionales y experimentales que deben constituir su correlato, en cuanto realidad efectiva del mundo, "no existe apenas semejanza, pero debe haber correspondencia” (FHH, IV, 527). En nota a pie de página y citando a Weyl, como veremos en su momento, esta correspondencia ni siquiera alcanza el grado de un "paralelismo". Tal como expone en ¿Qué es filosofia?, curso universitario impartido en 1929, el conjunto teórico y la realidad material representada por aquél son "como dos idiomas diferentes que permite únicamente la traducción. La física no es más que correspondencia simbólica." (¿QF?, VII, 303)

La idea de que la ciencia física - la ciencia ejemplar, como reiteradamente señala, que nos desvela la realidad material del Universo-, se ha convertido en una forma de conocimiento cuyo sentido ha dado un giro radical, desde el "primero, espontáneo y pleno» (IPL, VIII, 81), que tradicionalmente se le venía atribuyendo, atravesará ya toda su obra posterior. El conocimiento que la ciencia física proporciona ha desembocado en un "conocimiento ciego", simbólico, que "en vez de conocer la cosa real, posee el conocimiento de su signo en un sistema de signos o símbolos" (IPL, VIII, 81). Se trata de un saber al que caracteriza como "casero, inmanente, intrahumano" (HS, VI, 48) que, a sus ojos, "no nos pone en contacto con ninguna trascendencia" (HS, VI, 48). La naturaleza estudiada por el físico ha acabado por ser «un aparato de su propia fabricación que interpone entre la auténtica realidad y su persona» (HS, VI, 48). Esta idea central de la esencia del conocimiento simbólico aparece muy bien 
sintetizada por medio de una analogía que Ortega nos propone. Dicho conocimiento puede compararse con el que cabe obtener de las prendas depositadas en un guardarropa, a través de la fichas numeradas que las ubican en su recinto. Es éste un ejemplo que expone en tres ocasiones diferentes ${ }^{7}$, a lo largo de su labor intelectual. Considerando el número de años que las separa y el dilatado período temporal abarcado, se nos revela como un hilo conceptual muy persistente dentro del entramado de su pensamiento. El filósofo madrileño asimila, pues, la "teoría física" al conjunto de fichas; y la "naturaleza" al de las prendas de vestir. Con el agravante, como él mismo expone, de que aun la equiparación, en cuanto consistencia material, que ambas clases poseen, no tiene parangón en el conocimiento reflejado por la ciencia física. De ahí que concluya definiendo al físico como una especie de "guardarropista ciego del universo material".

Con los rasgos apuntados nos parece suficiente para una primera aproximación, teniendo en cuenta que los dos vectores temáticos expuestos constituyen el núcleo de la concepción orteguiana sobre el conocimiento científico. Será menester, no obstante, señalar también algunos ya mencionados, de menor entidad, sin duda, pero importantes para nuestra indagación. De ellos nos ocuparemos con posterioridad.

\section{Ortega en sus textos}

A fin de enmarcar convenientemente nuestra labor, acaso sea de utilidad efectuar una sucinta recopilación de las manifestaciones explícitas en la obra de nuestro filósofo acerca de este físico y matemático, a quien no escatima los elogios. Como al entrar de lleno en el núcleo temático habrá ocasión, y aun necesidad, de acudir a los textos de Ortega directamente conectados con esa línea central, en esta fase preliminar sólo intento esbozar una visión panorámica que abarque, en primer término, cuantas referencias pueden hallarse antes de la fecha de 1928. Inmediatamente después tampoco será ocioso fijarnos en aquellas otras que, sin una relación tan directa con el vector central del trabajo, tienen como referente al aludido físico y en las que, generalmente - tanto antes como después de la citada fecha de 1928 - se le asocia al matemático holandés Brouwer en el mantenimiento de posiciones «intuicionistas» en el campo de intersección de la lógica y de la matemática.

7 En (¿QF?, VII, 302), (BF, V, 277) e (IPL, VIII, 80). 
La primera referencia que encontramos en la obra orteguiana data de 1923. Expresa palmariamente el espíritu que animaba su empeño, consistente en resaltar todos aquellos acontecimientos intelectuales del momento que, desde principios de siglo, convergían en un proceso de superación del idealismo, matriz nutriente de una Modernidad ya agotada. Verdadera tarea "a la altura de los tiempos", a la que él mismo contribuía, entre otras cosas, haciéndose eco, que propagaba ampliado, de las ideas más importantes que la ciencia iba sacando a la luz. $Y$, por supuesto, la teoría de la relatividad einsteniana poseía un rango de primerísima fila. Así, refiriéndose a «la más clara y patente» tendencia profunda de la teoría de la relatividad, afirma:

«Mientras el pasado utopista lo arreglaba todo recurriendo al infinito en el espacio y en el tiempo, la física de Einstein - y la matemática reciente de Brouwer y Weyl lo mismo- acota el universo." (SHE, III, 241).

En nota a pie de página alude Ortega a una conferencia suya, pronunciada en 1914, donde pronosticaba una época posterior de mayor atención a "lo discontinuo y diferencial». Hallamos referencias a los trabajos de Planck sobre los cuantos; al principio general de la relatividad einsteniana (1915); a la obra de Uexküll (1913); y a la de Spengler (1918). Y se manifiesta de este modo:

«En fin, la misma matemática, que era la matriz de la idea de continuidad, empieza a afirmar la necesidad de renunciar a ella y afianzarse en lo discontinuo. Las dos cabezas más geniales de matemáticos que hoy existen Brouwer y Weyl- trabajan a estas horas en ello." (A, III, 304, n)

En el año 1925 y en un artículo acerca de la resurrección de la mónada, se refiere Ortega a un folleto que, detalle significativo, le envía el propio Weyl cuando todavía no había salido al comercio en Alemania, de título ¿Qué es la materia? Nuestro filósofo se expresa en los siguientes términos:

"Hermann Weyl es uno de los heráclidas, uno de los gigantes de nuestra generación, que con Einstein, Eddington, Bohr, Miss, etc., anda afanado en construir un nuevo cosmos físico. Pues bien, en el folleto de Weyl se llega a la sorprendente conclusión de que la nueva física conduce a una idea "inmaterial" de la materia, cuya expresión más adecuada sería la mónada de Leibniz.» (RrM, III, 340)

El hilo temático discurre sobre los cambios profundos que van haciéndose patentes en la física, ciencia de la que destaca su carácter constitutivo y domi- 
nante de «funcionalista" y "relacionalista». Donde, como afirma, «se trata de disolver la realidad en factores de espacio y tiempo, que son relaciones» (RrM, III, 341). Claro que dicha condición coloca a esta ciencia en posición secundaria, pues, como concluye,

"Si la relación supone cosas que se relacionan, la ciencia física o de relaciones supone otra ciencia superior de las cosas relacionadas. Este es el espíritu que anima al folleto de Weyl. Como él, las mejores cabezas creadores con que hoy cuenta Europa se orienta, sin «desvirtuar la física», hacia una metafísica. Y la metafisica es, ante todo, meditación de las sustancias." (RrM, III, 341)

Y en nota a pie de página efectúa una declaración que le distancia de la inspiración kantiana:

"Pero no relaciones impuestas por la mente a las cosas, como Kant quería, sino relaciones de naturaleza objetiva. La nueva física relativista se aproxima más a Aristóteles y Santo Tomás que a Kant.» (RrM, III, 341)

En su libro de mayor difusión, La rebelión de las masas, hallamos unos párrafos dedicados a subrayar la fragilidad de un producto histórico tan sofisticado cual es la ciencia física, destacando al tiempo su proyección instrumental. Creo que son las suyas palabras dignas de reflexión, siendo expresión de unos temores que han conformado en profundidad nuestra propia época, situada bajo un alto riesgo para la continuidad de la civilización, por obra de una confrontación atómica y que hoy todavía persiste, no por larvada menos ominosa. De esta manera se pronuncia:

«Hermann Weyl, uno de los más grandes físicos actuales, compañero y continuador de Einstein, suele decir en conversación privada que si se murieran súbitamente diez o doce determinadas personas, es casi seguro que la maravilla de la física actual se perdería para siempre en la humanidad. Ha sido menester una preparación de muchos siglos para acomodar el órgano mental a la abstracta complicación de la teoría física. Cualquier evento pudiera aniquilar tan prodigiosa posibilidad humana, que es además base de la técnica futura." (RM, IV, 174, n)

En una serie de obras diferentes, Ortega se ocupa de un tema central de la época: la crisis de fundamentos que afecta a la ciencias centrales. En esta línea podemos hallar un conjunto de referencias al papel que juega el lógico-matemático holandés Brouwer - a menudo asociado a Weyl por el filósofo madri- 
leño-, que tienen como núcleo la anticipación del fracaso del programa logicista. El primero de esos textos data de 1929. Aludiendo al «nuevo temperamento científicon, sobre todo en la matemática, dice lo siguiente:

"Su supeditación a la lógica había llegado en las últimas generaciones hasta hacerse casi identidad. Pero he aqui que el holandés Brouwer descubre que el axioma lógico llamado del "tercero excluso" no vale para las cantidades matemáticas y que es preciso hacer una matemática "sin lógica", fiel sólo a sí misma, indócil a axiomas forasteros.» (¿QF?, VII, 306)

Igualmente cabe apreciar otras orientaciones, generadas por ese «terremoto" que es la crisis de fundamentos, en el texto que a continuación transcribimos:

"Renunciemos alegremente, valerosamente, a la comodidad de presumir que lo real es lógico y reconozcamos que lo único lógico es el pensamiento. Ya el objeto matemático presenta simas de ilogismo tan tremendas como el "laberintos de las dificultades de lo continuo" y todos los problemas que inspiraron a Brouwer el intento de derrocar el principium tertii excluso. La física nos sorprende hoy dramáticamente con los estados de in-identificación de los elementos atómicos.» (HS, VI, 30)

El mismo hecho de "no saber que hacer", que él constataba al comienzo de los años cuarenta en el orbe de la política, lo compara con la conmoción que afectaba a los fundamentos de las ciencias centrales:

"Lo mismo pasa en el otro extremo, en el polo opuesto a la política: el físico, ante la situación interna a que ha llegado su ciencia, no sabe qué hacer con la física; ni el matemático con la matemática; ni el lógico, que al advertir cómo vacila la base de sus milenarios principios, no sabe qué hacer con ella, con la soi-disant lógica, como la llama uno de sus más geniales cultivadores actuales, el matemático holandés Brouwer." (RH40, XII, 152)

En ese contexto de crisis de los principios constitutivos de las ciencias es donde se producen sus afirmaciones sobre el intuicionismo de Brouwer. Se trata de una idea fundamental que, matizada de una u otra forma, cobró su auténtica relevancia tras el trabajo clásico de Gödel, que igualmente tuvo adecuado reflejo en su obra posterior. Dice Ortega:

«Brouwer, el genial matemático que ha dado el último gran impulso a la lógica, deća no hace mucho que la matemática es por completo independiente al lenguaje matemático. Y nótese que aquí se habla, no del lenguaje vulgar sino del lenguaje simbólico del álgebra y hasta de la logística, que pre- 
tendía la máxima exactitud... En efecto, la idea que del hecho matemático tenemos es más rica y más henchida que todas las definiciones que podamos dar de ella, que todas las formas o combinaciones de signos o proposiciones por las cuales nos es posible expresarlas.» (RH40, XII, 168)

Le impacta lo que considera "inaudito». La, en cierta medida, descalificación de la Lógica, realizada por quien el filósofo español tiene en alta estima:

"El genial matemático holandés Brouwer-, ha podido referirse a la lógica llamándola desdeñosamente la soi-disant lógica. ¡La lógica soi-disant ¡ $\mathrm{Se}$ percatan ustedes bien, bien de la enormidad que esto significa; porque eso significa, lisa y llanamente, que la lógica es i-lógica, por tanto, que no hay lógica..., es lo que llamo - y no me parece exagerada la imagen - el terremoto en la razón." (RH44, XII, 288)

Idea ésta sobre la que vuelve pocas páginas adelante para señalar que si esa amenaza de volatilización de la lógica llegara a cumplirse

"y no se le hallase remedio, dejaría de haber cosas que son verdaderas y cosas que son falsas, es decir, que nada habría con su propio y preciso ser, por tanto, que esa luz en la oscuridad primaria del vivir que es la verdad se apagaría y todo sería profunda tiniebla.» (RH44, XII, 290)

A todo ello viene a añadirse la compleja problemática inferida desde la nueva teoría física y su relación con la realidad, como reafirma en otro de sus textos, a fin de que

"el lector reciba el choc adecuado y entre en sospecha de que algo muy grave acontece en los senos profundos de las ciencias ejemplares." (PWD, VII, 65)

Finalizamos este periplo con la última alusión al intuicionismo, incluida en su libro sobre Leibniz. En la exposición acerca de los diferentes «modos de pensar" y refiriéndose a los caracteres constitutivos de la Matemática actual, matiza: "por lo menos la Matemática que podemos llamar canónica». A lo que viene a añadir, en nota a pie de página:

«Se refiere esta reserva a la dirección intuicionista de Brouwer y otros, que es todavía un ensayo, aunque bastaste para plantear graves cuestiones a la tendencia dominante en la historia moderna de la matemática, que ha sido un progresivo logicismo.» (IPL, VIII, 96, n 3) 
De esto último cabría acaso inferir que Ortega no ha tomado en consideración, al menos explícitamente, la línea formalista, axiomatizadora y simbólica, puesta a punto por Hilbert y que Hermann Weyl contempla en su artículo de 1927 como una alternativa real a las limitaciones de la escuela intuicionista. Sin embargo, ese posible acortamiento de radio implicado en la visión del catedrático madrileño, queda circunscrito a la esfera lógico-matemática. Como ya hemos visto, su enfoque de las consecuencias de la física, concebida como paradigma de la Ciencia, le conduce a adoptar la concepción de la ciencia como construcción simbolica.

\section{Constructivismo}

Intentemos mostrar ahora aquellas ideas del físico alemán que, plasmadas en su trabajo de referencia, aparecen como fuentes probables de algunos desarrollos de la reflexión orteguiana. Hermann Weyl, como él mismo manifiesta, se muestra "primordialmente interesado en la investigación matemática» 8 . Cuando, en su artículo, se ocupa de otras ciencias, su reflexión presupone una fundamentación en las descripciones efectuadas en la primera parte, que versan sobre la matemática. De ahí que, si queremos ir a las raíces del sentido de la noción de la ciencia como construcción, vector conceptual clave del pensamiento orteguiano sobre la ciencia, no reste otra alternativa que acudir al campo de la matemática. Seguir al físico-matemático germano por todos los derroteros transitados en su obra sería tarea que, como ya aludimos, nos alargaría en exceso. Nos limitaremos, pues, a los núcleos temáticos que encuentran eco en la filosofía del intelectual hispano.

El primero y más sustantivo es esa noción de construcción. Sobre ella podemos encontrar numerosas alusiones en el texto de Weyl, relacionadas con múltiples y muy variadas proyecciones hacia los diversos ámbitos de las ciencias naturales exactas. Uno de los más básicos es el campo de los números, pues se trata del pilar o soporte fundamental sobre el que se levanta el edificio de la aritmética. Tomándolo como referente, Weyl nos proporciona la figura de unas «modalidades básicas" de lo que, desde su visión, constituye el "conocimiento constructivo". Merece la pena transcribir esta descripción completa, pues la caracterización aquí realizada refleja con bastante fidelidad la esencia o consis-

8 Op. cit., p. 245. 
tencia de la actividad constructiva. Y no sólo en orbe de la matemática, ciencia formal cuyos entes son objetivos no-reales, sino que bien podríamos extenderla - mutatis mutandi- a cualesquiera otros contextos que admitan la posibilidad de este tratamiento teórico:

«1. Adjuntamos a lo que es dado ciertos caracteres no manifiestos en el fenómeno, pero que son el resultado de ciertas operaciones mentales. Es esencial que la actuación de estas operaciones sea universalmente posible y que su resultado esté inequívocamente determinado por los datos. Pero no es esencial que las operaciones que define el carácter sean realmente llevadas a cabo.- 2. Por la introducción de símbolos los asertos son separados de tal forma que una parte de las operaciones es transmitida a los símbolos haciéndose independientes de los datos y de su existencia continuada. Por lo tanto la libre manipulación de los conceptos contrasta con su aplicación, las ideas se separan de la realidad y adquieren una independencia relativa.- 3 . Los caracteres no se exhiben individualmente en la forma en que se manifiestan, pero sus símbolos se proyectan en la pantalla de una variedad ordenada de posibilidades que pueden generarse por un proceso fijo y está abierta hacia el infinito.» 9

Moviéndonos todavía en la órbita de la matemática, podemos apreciar este constante recurso a la operación constructiva, p. e., como cuando el autor nos hace notar que ula posibilidad de construcción y el carácter individual de los números los califica para la representación teórica exacta de la realidad" 10 . Desde su perspectiva, subraya el método de la definición matemática constructiva como uno de los que operan en esta ciencia. Si en aritmética el proceso básico constructivo es el de la inducción completall — también denominado "inducción matemática»12, como él mismo aclara-, capaz de ir generando, por métodos recursivos, la sucesión de los números naturales. Igualmente se refiere a otros ejemplos, como el de función, o al de los "puntos de infinito" en geome-

9 Op. cit., p. 41.

10 Op. cit, p. 8.

11 Un eco de la importancia de esta noción se puede encontrar también en Ortega y quizá sea de interés recordarlo. Reverbera en la alusión que efectúa acerca de la inducción como "prueba integral". Refiriéndose a los "modos de pensar" subyacentes a las diferentes filosofias, manifiesta al respecto: «Espero pronto mostrar con detalle la verdad del aserto en dos casos excepcionales que, por serlo, pueden valer por sí solos como prueba para todo el resto de las filosofias, como en la inducción completa de las matemáticas la prueba por $n+1 \cdots$. (IPL, VIII, 90, n.)

12 Op. cit., p. 37. 
tría. Lo que subyace a este método es la introducción de elementos ideales. Hay un caso especial que nos resalta, dividido a su vez en dos líneas convergentes y que no conviene echar en saco roto. Se trata de un proceso que describe como definición por abstracción matemática, al que cabe correlacionar con el de abstracción primaria. Actúan ambos en diferente ámbito, en el de la matemática el primero, como su denominación indica; haciéndolo el segundo en el orbe más general de la realidad. Mas en ambos casos,

«la transformación de una característica común en un objeto ideal, por ejemplo, de la propiedad 'rojo' en un 'color rojo' objetivizado, del cual 'participan' las cosas rojas, es un paso esencial $\mu \varepsilon \theta \varepsilon \xi 1 \zeta$ de Platón)" 13.

Ahora bien, un poco más adelante, Weyl mismo igualmente va a extender a las relaciones, por generalización, esta función - ahora sólo atribuida a las propiedades-, de "definir elementos ideales" ${ }^{14}$. La importancia de todo lo anterior queda de manifiesto al considerar que, p. e, en el caso de la matemática, desemboca en una de sus dimensiones particularmente problemática para la filosofia de esta ciencia: la teoría de conjuntos. Weyl afirma que «la definición creativa", como denomina -en el parágrafo 2 de la sección dedicada a las matemáticas- al proceso constructivo en este área particular de la ciencia,

"no es otra cosa que la transición de una propiedad a un conjunto, por lo que la construcción matemática de nuevas clases de objetos ideales puede caracterizarse en forma bastante general como formación de conjuntoss 15 .

En el apartado dedicado a la Metodología, ya en la segunda parte de su artículo, donde se ocupa de la formación de conceptos, y en uno de los numerosos comentarios de corte histórico que lleva a cabo, el físico y matemático centroeuropeo depurará aún más su concepción. En ciencias tales como la zoología o la botánica descriptivas opera un proceso abstractivo de inspiración aristotélica en que "sólo se toman en cuenta los objetos realmente existentes» ${ }^{16}$. El concepto conformador de las clases resultantes requerirá "tantas 'connotaciones' como sea posible» ${ }^{17}$ y ello de "acuerdo con el testimonio de la experiencia» ${ }^{18}$. Ahora

\footnotetext{
Op. cit., p. 13.

Op. cit., $\mathrm{p} 14$.

Op. cit., pp. 13-14.

Op. cit., p. 170.

Op. cit., ibid.

Op. cit., ibid.
} 
bien, en el caso de la formación "físico-matemática o 'funcional' de conceptos", nos dice que

«no toma lugar ninguna abstracción, sino que hacemos variables ciertas características individuales que pueden variarse continuamente..., y el concepto no se extiende a todos los objetos reales, sino a todos los objetos posibles así obtenidos» 19 .

La conclusión obtenida nos destaca un aspecto que se muestra de gran interés intrínseco, debido a sus implicaciones:

"Así los objetos particulares que caen bajo el concepto funcional han de ser generados, y no debe hacerse la pregunta de si un objeto cae bajo él con la esperanza de que 'los hechos' han de contestar necesariamente con un claro sí o no." 20

Forma de proceder que, discurriendo desde lo general a lo específico, se halla grávida de resonancias platónicas, como el autor encuentra oportuno subrayar.

Mas el físico-matemático alemán nos alerta de un peligro, de una ilusión - cuyo padecimiento atribuye temporalmente a figuras de una entidad de calibre tal como "Dedekind, Frege y Russell». Consistiría ésta en una confusión epistemológica, pero de trasfondo ontológico, que llegaría a hacerse patente en los debates surgidos en la filosofía de la matemática en torno al núcleo de problematicidad enquistado en la teoría de conjuntos. Para Weyl es claro, y así lo expone, que por medio de los procesos constructivos empleados no se puede pensar que «se ha alcanzado una representación concreta de los objetos ideales» 21 . Como se puede constatar a través de este elemento central de constructivismo esbozado, se trata de una verdadera toma de posición en el problema ontológico - con proyecciones lógicas y epistemológicas- planteado en el seno de la filosofía de matemática - también en el de la lógica- y que no deja de ser trasunto modernizado del secular debate nuclear de la filosofía acerca de los universales.

En otro de los apartados de su trabajo, el citado Weyl efectúa un breve recorrido, panorámico podríamos ańadir, sobre la matemática intuitiva. Como

\footnotetext{
19 Op. cit., p. 170.

20 Op. cit., p. 170.

21 Op. cit., p. 14.
} 
antes hemos podido comprobar, cabe rastrear referencias de Ortega - ya en el año 23-, en las que los nombres de Weyl y de Brouwer quedan asociados. Incluso en una ocasión, en 1929, los une expresamente bajo la rúbrica del «intuicionismo". Carecería de utilidad entrar ahora en disquisiciones sobre este aspecto. Bástenos con hacer una breve alusión, al paso y sin detenernos. Weyl pone de relieve alguno de los más importantes componentes que caracterizan a esta particular «escuela» de la filosofía de la lógica y de la matemática. El sistema matemático del matemático holandés Brouwer enfronta una particular dificultad de orden general, surgido en la teoría de conjuntos, y que la escinde en dos concepciones divergentes, logicismo e intuicionismo, cuyos respectivos focos consistirían en considerar el conjunto "como un agregado cerrado de objetos que existen por sí mismos" 22 , frente a la noción que lo contempla como "un campo de posibilidades constructivas» ${ }^{23}$, aplicable igualmente a otros géneros de entes matemáticos. Desde la perspectiva intuicionista, no cabe conferir a las meras aseveraciones existenciales sobre entes matemáticos la naturaleza de descripciones de hechos, a no ser que vayan acompañadas de los expedientes constructivos que nos muestren la manera de generar dichos objetos. Como manifiesta Weyl, «sólo en virtud de una construcción efectiva, una prueba ejecutada, adquiere sentido una aseveración existencial" 24 . A lo que añade, en alusión a los teoremas existenciales de las matemáticas, "lo que tiene valor no es el teorema como tal sino la construcción llevada a cabo en su demostración; sin ella el teorema es una sombra vacía." 25

Lo que se halla en el centro del debate es una réplica a una concepción de ascendencia realista, a la que también se ha designado con el término de platonista. En efecto, cuando se aceptan las aseveraciones existenciales de forma irrestricta se coloca uno ya "del otro lado" - como dice Weyl-, pues se propone el sistema de los números - pongamos como ejemplo, para seguir a dicho científico- como «un dominio de existencias absolutas 'fuera de este mundo' y del cual sólo destellos, aquí y allá, se reflejan en nuestra consciencia» ${ }^{26}$. El universo del discurso acota el problema de la configuración óntica de los objetos propios de esa región ontológica, una de cuyas denominaciones sería la del "tercer reino" fregeano, o mundo objetivo no-real.

\footnotetext{
22 Op. cit., p. 55.

23 Op. cit., p. 55.

24 Op. cit., p. 56.

25 Op. cit., p. 56.

26 Op. cit., p. 42.
} 
Para la escuela intuicionista, la "intuición matemática original» radica en "el principio de inducción completa (como instrumento de definición o inferencia), no encerrado en una fórmula sino aplicado concretamente en cada paso". Añade a esto nuestro matemático también el conocido rasgo de la inaplicabilidad del principio lógico de tertium non datur, derivado — según Brouwer- de haber abstraído la lógica clásica de una matemática conjuntista finitista en que se podían enumerar los elementos por exhibición; por haberla considerado con "una existencia a priori independiente de las matemáticas"; y por razón de proyectarla, "sin justificación», a una teoría de conjuntos infinitista. El límite de espacio impide que podamos adentrarnos en aspectos particularmente sugerentes, como puede ser el del análisis del continuo. Las conclusiones a que Weyl arriba sobre esta particular concepción nos parecen sumamente interesantes, habida cuenta de su aludida vinculación con Brouwer, cabeza de la "escuela intuicionista", que sobre él establece Ortega. En primer término, encontramos en Weyl un explícito reconocimiento de los valores positivos de dicha escuela, concordando en que se dan unas bases sólidas para el conocimiento, enfocado éste desde el punto de vista no demasiado lejano de la función cognoscitiva de la intuición, a su vez convertida en el elemento central de la fenomenología husserliana, con sus noción concomitante de evidencia inmediata, y ya sea aquélla fenoménica o categorial. Concede, pues, que esta concepción matemática llega a alcanzar la mayor claridad intuitiva. Tal como nos dice,

«logra desarrollar los comienzos del análisis en forma natural, conservando siempre íntimo contacto con la intuición en forma mucho mejor de la conseguida hasta entonces" 27 .

Ahora bien, aun adscrito plenamente al constructivismo, el camino de Weyl no se detiene en los confines del intuicionismo y traspasa decididamente sus fronteras. Él siente la necesidad de ir más allá, mostrándonos otro camino que conduce al otro lado de los límites, demasiados cercanos, que nos marca la intuición. Subrayemos sus reservas ${ }^{28}$, que se hacen explícitas, pues reducirse a esa

27 Op. cit., p. 60.

28 Conviene también mencionar la ausencia en la obra orteguiana de cualquier alusión en este mismo sentido de limitación que acompaña al intuicionismo. En ningún momento cabe hallar un eco de cautela por parte de Ortega. Nuestro filósofo toma en bloque compacto tanto las luces como las sombras, como se nos hace patente en un texto acerca de la construcción de la matemática por la lógica: "Me refiero al ensayo que Brouwer y Weyl hacen de demostrar la discrepancia parcial que hay entre la consistencia del número y la de los conceptos, por tanto, la im- 
concepción lógico-matemática significa permanecer bajo el cobijo de la seguridad que proporciona la validez que de ella se deriva. Aunque, al mismo tiempo, esto exige quedarse constreñido a una esfera de radio no excesivamente amplio. Pues ocurre que, a pesar de esa referida ventaja,

"no puede negarse que al llegar a teorías más avanzadas y generales la inaplicabilidad de las simples leyes de la lógica resulta en una torpeza casi insoportable. Y el matemático observa con dolor que el edificio que creía construido de bloques de concreto se esfuma ante sus ojos» ${ }^{29}$.

Situado en esta encrucijada, Weyl se efectúa la pregunta coherentemente oportuna: "¿No hay manera de escapar a estas consecuencias radicales?» 30 . Una de las posibles rutas de salida, subrayada a lo largo de numerosas páginas de su trabajo, toma el rumbo del formalismo del método axiomático, puesto a punto por Hilbert, y cuya esencia consiste en ser una construcción simbólica. En lo que respecta al aspecto simbólico de dicha configuración teorética, nos ocuparemos con más detalle en el apartado siguiente, mientras que ahora continuamos poniendo el acento sobre su característica constructiva. La formulación clásica de este método axiomático se debe al citado Hilbert y cristaliza en Grundlagen der Geometrie, como nos recuerda Weyl ${ }^{31}$, destacando, al tiempo, que este género de procedimiento no es privativo de las ciencias formales, encontrando igualmente aplicación en algunas partes de los estudios de Galileo, o en los de Huyghens, o, entre otras ramas de la física contemporánea, en la teoría del espacio-tiempo de la relatividad especial. Caracteriza a esta conformación metódica,

"coleccionar todos aquellos conceptos básicos así como todos aquellos hechos básicos a partir de los cuales se pueden derivar por definición y deducción respectivamente todos los conceptos y teoremas de una ciencian 32 .

posibilidad de una matemática lógica o formalista, la necesidad de una matemática fiel a la peculiaridad de su objeto, que ellos llaman «intuicionista», una matemática que no sea lógica, sino precisamente matemática»" (¿QF?, VII, 326-327). Aun en la hipótesis de que en el artículo de 1927 no hubiera plasmado Weyl las limitaciones en cuestión, lo cierto es que los desarrollos efectuados por el físico y matemático alemán en su artículo son un reconocimiento indudable de la formalización axiomatizadora. El carácter simbblico resultante de la aplicación de esta metodología de la ciencia opera igualmente en la visión aceptada y manifestada por el pensador madrileño a lo largo y ancho de obra escrita.

$\begin{array}{ll}29 & \text { Op. cit., p. } 60 . \\ 30 & \text { Op. cit., p. } 60 . \\ 31 & \text { Op. cit., p. } 22 . \\ 32 & \text { Op. cit., p. } 20 .\end{array}$ 
Parece significativo que acuda a la opinión de Husserl para conferir a esta idea mayor realce, pues inmediatamente después añade que la teoría científica, caso de hacerse posible encajarla en ese molde axiomático, "es definida", según la opinión del fundador de la fenomenología. El desarrollo de este método, deduciendo a partir de los axiomas, produce "proposiciones pertinentes generales $y$ verdaderas", lo que establece unos límites demarcadores en cuanto acotación estricta de lo realmente inferible en cada campo axiomático, bien sea en razón de su propia especificidad o por tratarse de casos individuales, cuyo tratamiento poseerá este mismo carácter, aun subsumido en el marco axiomático considerado.

Pasa también revista el científico alemán a las propiedades metateóricas fundamentadoras de este método axiomático, cuales son la consistencia, la completitud y la independencia, hallándose ausente, sin embargo, la decidibilidad, lo cual quizá se deba a que está proyectando el sistema axiomático al conjunto de las ciencias y no sólo a la lógica formal. Al efectuar el referido recorrido, afirma la indubitabilidad de la consistencia cuando es el caso que los axiomas reflejen "la verdad con respecto a un cierto campo de objetos". Mas esa cierta cautela o, por mejor decir, ese afán de adecuación a lo que es o consiste la realidad auténtica, sin pretender en momento alguno desvanecer las disonancias entre un saber, a veces pretencioso, y el mundo real, impele a este sabio, de acendrada honestidad intelectual, a una confesión que deseamos subrayar como vector muy destacado de la más que probable influencia que se haya proyectado hacia el pensamiento orteguiano y que constituye un núcleo constructivista de pensamiento cuya importancia no sería fácil exagerar. Dice así Weyl:

"Pero los hechos no siempre contestan a nuestras preguntas tan inequivocamente como sería deseable; rara vez una teoría científica da una versión fiel de los datos sino que casi siempre es una construcción audaz.» 33

Igualmente vamos a encontrar esta noción de construcción teórica en el orbe de la ciencia natural, singularmente en la física, transvasada desde el ámbito de las matemáticas. También aquí será imperativo reducirnos a nuestro particular hilo de Ariadna, dejando al margen otras muy interesantes facetas tratadas por el destacado físico-matemático.

Una de sus afirmaciones de mayor entidad respecto de este punto de la constructividad, ya mostrado en el interior del orbe matemático, la lleva a ca-

33 Op. cit., p. 22. 
bo al poner de relieve que "espacio intuitivo" y "tiempo intuitivo", al igual que las "cualidades sensorias" 34 no constituyen el "medio adecuado" para la construcción que del mundo externo realiza la ciencia física. Según nuestro autor lo ve, aquél debería ser sustituido, "en el sentido aritmético abstracto", por un material idóneo, el continuo tetradimensional. Se remite al caso de los colores, a los que ya ni siquiera habría que caracterizar —cual hacía Huyghens- como oscilaciones del éter, sino que en la concepción de la física actual quedaban descritos por

«meras funciones matemáticas periódicas que dependen de cuatro variables que como coordenadas representan el medio del espacio-tiempon 35 .

Es ésta una expresión muy interesante, pues nos revela palmariamente cual es la nueva idea que marca el rumbo de una física donde los acontecimientos o los hechos quedan reducidos a mera formulación numérica, abstracta en sumo grado. Tal como Weyl enfatiza, y esto es algo que conviene destacar a fin de comprender la nueva esencia o consistencia de la ciencia física:

«Lo que queda finalmente es una construcción simbólica del mismo tipo de las que realizó Hilbert en matemáticas.» 36

Este ideal de emancipación de la física sobre el espacio y el tiempo intuitivos sólo habría sido completado por la teoría general de la relatividad, en opinión de nuestro autor. Sobre dicho punto se debería tener en cuenta la fecha de elaboración, en que todavía, aun estando ya muy próxima, no había tomado carta de naturaleza definitiva la nueva interpretación del mundo físico implicada por la más reciente teoría cuántica, acontecimiento que tendría lugar en el otoño del año 1927. Así pues, el pensamiento de Weyl se condensa en torno a la idea de que hay una "física constructiva" ${ }^{37}$, a cuyo concurso concurre, p. e., una geometría que se convierte en "base ideal» para «la astronomía y la física atómica» 38 .

Entre las múltiples direcciones de su reflexión, nuestro físico, "compañero y continuador de Einstein» — como Ortega le denomina—, se detiene en el te-

34 Noción que aquí englobaría tanto a las cualidades secundarias, de más acusado matiz subjetivo, como a las cualidades primarias, en mayor medida escoradas hacia la vertiente puramente objetiva.

35 Op. cit., p. 127.

36 Op. cit., p. 127.

37 Op. cit., p. 162.

38 Op. cit., p. 163. 
ma de la formación de conceptos, describiendo las fases contenidas en el análisis de la naturaleza y a través de las cuales van siendo aquellos generados. Proceso que, como es evidente, parte de lo más simple o intuitivamente dado o presentado al sujeto. Sólo mencionaremos un punto que nos parece sugestivo. Del estudio de lo que aparece ante el sujeto, infiérese a veces la existencia de "algo escondido", de lo latente que explicaría lo patente. Ello conduce - tal como afirma el autor- a postular «elementos hipotéticos", poniendo como ejemplo a los átomos, fuerzas, campo eléctrico, etc. Por medio de un análisis caracterizado por una exploración cuantitativa, cristalizada en funciones matemáticas, proseguido por una observación cada vez más depurada, se va accediendo a las "leyes básicas" subyacentes al orden de la realidad. Así, nos dice, "aparecen los conceptos constructivos correctos que sirven para describir la naturaleza objetivas ${ }^{39}$. Como caso de ejemplo típico de concepto físico constructivo recurre al concepto galileano de masa, reflexión que le lleva a la siguiente conclusión:

"La ciencia natural constructiva tiene como tarea general asignar a los objetos caracteristicas cuantitativas constructivas (dependientes sólo del objeto peto no necesariamente observables) tales que hagan su comportamiento, bajo circunstancias descritas por características del mismo tipo, completamente determinado y predictible con base en las leyes naturales., 40

Este análisis de la formación de conceptos, desgranando reflexiones sobre los de masa, cantidad de movimiento y fuerza, le conducen a la convicción de que la "interpretación metafísica" de la naturaleza queda modificada por las conclusiones de la construcción teórica. Corolario necesario de todo ello es que: "El carácter constructivo de las ciencias naturales se ha vuelto obvio» ${ }^{41}$. Expresión rotunda que nos evita mayores comentarios y permite trasladar nuestra atención al otro vector de la concepción sobre la ciencia.

\section{Simbolismo}

El pensamiento intuicionista de Brouwer, de índole constructivista, se halla interesado, primordialmente, en asegurar la característica de veracidad. Sin embargo, su potencialidad de desarrollo alcanza unos límites infranqueables, co-

\footnotetext{
39 Op. cit., p. 166.

40 Op. cit., p. 168.

41 Op. cit., p. 171.
} 
mo Weyl apunta, quedando confinado en un horizonte de radio quizá no excesivamente dilatado. A este respecto, Weyl recoge la opinión de Hilbert, más centrado, a su vez, en la noción de consistencia, acerca de que dicho tipo de pensamiento intuitivo

"es incapaz de fundamentar las formas transfinitas de deducción matemática, y que ninguna de las proposiciones transfinitas de la matemática pueden justificarse como verdades materiales evidentes» 42 .

La respuesta hilbertiana a esta cuestión, la formulación axiomatizadora, es una matemática simbólica. Y la importancia radical que ello tiene deriva de la situación central que le viene siendo atribuida a la matemática por obra de la Modernidad. En el fondo de esta nueva concepción lo que subyace es una cierta disolución del referente. Como aduce Weyl, «los símbolos no han de ser simbólicos de algo". De ahí que pase a primer plano el principio de consistencia, en detrimento del rango reconocido a la veracidad, tal y como Weyl apunta. La formalización acometida gira ahora en torno a «juego de símbolos que siga ciertas reglas fijas» ${ }^{43}$. De esta forma, nos hallamos ante unas matemáticas cuyas fórmulas se construyen con símbolos y, por ello, "no siempre admiten una interpretación material” 44. Ha sido necesario introducir 'proposiciones ideales' con la finalidad de "restablecer artificialmente la validez de las reglas lógicas simples», que habían dejado de poseerla, según la escuela intuicionista, al proyectarse sobre los desarrollos conjuntistas de una matemática del infinito. $Y$ tal vez sea este el lugar más oportuno para destacar que Weyl considera el infinito como el centro vital de las matemática. El mismo lo declara muy sintéticamente: "matemáticas es la ciencia del infinito" 45 .

Aun no siendo factible acompañar al autor en su revista a los principios de esta matemática formalista hilbertiana, sí cabe, al menos, destacar la descripción que realiza del procedimiento recursivo, método constructivo que se echa de menos en las referencias orteguianas sobre el constructivismo de la teorización científica, por más que Ortega tampoco sea un filósofo de la ciencia. Igualmente, otro aspecto que conviene señalar es la alusión efectuada por Weyl acerca de una diferencia fundamental entre intuicionismo y formalismo. Para el

$\begin{array}{ll}42 & \text { Op. cit., p. } 61 . \\ 43 & \text { Op. cit., p. } 61 . \\ 44 & \text { Op. cit., p. } 61 . \\ 45 & \text { Op. cit., p. } 73 .\end{array}$


primero adquiere la inducción completa un carácter primordial, por cuyo conducto se «impide que las matemáticas se conviertan en una enorme tautología,, a la vez que "confiere a sus asertos un carácter sintético no analítico" ${ }^{46}$. Este elemento axial lo ocupa en el formalismo «la componente transfinita de los axiomas" 47 que, proyectado sobre las matemáticas, hace que esta ciencia no consista "en verdades evidentes, sino que es audaz construcción tébricas 48 .

Al hilo de esta discusión, Weyl nos recuerda el carácter de función instrumental que las matemáticas desempeñan en el campo de las ciencias naturales. $\mathrm{Y}$ en virtud de ello, extiende el área de confrontación a la física, asunto al que volveremos con posterioridad, destacando únicamente aquí la división que introduce entre "conocimiento fenomenológico» $\mathrm{y}$ «construcción teórica». El primero es visto con una perspectiva muy cercana a la de la filosofía husserliana y se basa en la función cognoscitiva de la «intuición». Véase su declaración al respecto:

«El conocimiento [fenomenológico] nos da verdad, su órgano es la 'visión' en el sentido más amplio. Aunque sujeto a error, es esencialmente definitivo e inalterable.» ${ }^{49}$

Conocimiento primario, pues, o antepredicativo, al que Ortega se referirá en numerosísimas ocasiones como aquél que tenemos de la cosas -en sentido lato- cuando entre ellas, con ellas, favoreciéndonos o dificultándonos, discurre nuestra vida, antes de que sobre ellas proyectemos nuestro pensamiento teórico, inquiridor, sobre su ser o consistencia. Por lo que al otro extremo concierne, la "construcción teórica", parece ésta orbitar alrededor de un único principio racional que admite formulación en sentido estricto: el de la "concordanciam, de la que también se ocupará el autor en otra parte de su libro. Este principio «implica consistencia», mas la «trasciende... al traer a la teoría en contacto con la experiencia” 50 . Pero en el caso de la matemática, cuyos entes no se hallan sometidos al imperio de los datos sensoriales, «se reduce a consistencian" 51 . Y añade algo que me gustaría dejar subrayado, ya que posee un cier-

\footnotetext{
46 Op. cit., p. 70.

47 Op. cit., p. 71.

48 Op. cit., p. 71.

49 Op. cit., p. 68.

so Op. cit., p. 137.

51 Op. cit., p. 68.
} 
to aire familiar que cualquier lector habitual de Ortega puede detectar: «su organo es la imaginación creativa» 52 . Efectivamente, es éste un tópico muy reiterado en la obra del filósofo madrileño.

Weyl efectúa una caracterización del formalismo que, si bien antes esbozada, no podemos por menos de reproducir, pues contiene otro vector conceptual que igualmente vamos a ver en Ortega. Dice así el matemático, refiriéndose al tipo de pensador de concepción formalista:

«Éste piensa en la matemática como consistente sólo de símbolos, los cuales no tienen significación verificable en la intuición mental o sensoria y que son manipulados de acuerdo con ciertas reglas fijas." 53

El término clave, que también transciende al pensador español, es el de "manipulación". Precisamente por el carácter simbólico que se ha infiltrado en la ciencia - tomando a la física como su paradigma - ésta ya no es conocimiento de la realidad sino que se ha reducido a una mera manipulación intelectual, la que después tendrá como resultado un aprovechamiento práctico de las cosas. Se produce, así, un desvanecimiento del conocimiento de la realidad, en el sentido tradicional que éste tiene - "presencia de la Realidad al pensamiento" (IPL, VIII, 81) - y cuyo modelo de referencia cabe situar en la concepción surgida de la filosofía griega.

No es parco nuestro físico-matemático a la hora de insistir sobre este tipo de actividad teórica que es el «formalismo axiomático». En una visión de síntesis, afirma que el hombre muestra un incontenible anhelo de trascender lo conocido fenoménicamente, que "nos impele hacia la totalización". Como nos dice, con magnífica imagen de una actitud que tiene en el orbe matemático el caso paradigmático del formalismo simbólico,

«la conciencia hace el intento de 'saltar sobre su propia sombra', dejar atrás lo dado y representar lo trascendentes 54 .

El traspasar los datos de la experiencia que conforman el conocimiento sensible es un viaje que únicamente puede hacerse a bordo de un vehículo muy especial, de naturaleza evanescente: el símbolo. Sólo a su través, como insiste

\footnotetext{
52 Op. cit., p. 68.

53 Op. cit., p. 72.

54 Op. cit., p. 73.
} 
Weyl, cabe acceder a ese más allá inasequible a los datos sensoriales. Se trata de una condición sine qua non:

"que estemos satisfechos con el símbolo y renunciemos al error místico de esperar que lo trascendente caiga jamás dentro del círculo iluminado de nuestra intuición" 55 .

Si bien el proceso constructivo-simbólico ha acontecido en el dominio de la matemática - sin olvidar tampoco el de la lógica - donde los problemas implicados en la noción del infinito han sido cruciales, no se ha detenido ahí la crisis, afectando, a la par, a los fundamentos de una ciencia de realidades, cual es la física. Weyl equipara ambas ciencias, tan dispares entre sí miradas desde otro ángulo, manifestando:

"Hasta ahora, sólo en matemáticas y física la construcción simbólico-teórica ha ganado esa solidez que la hace necesaria a aquellos cuya mente esté abierta a estas ciencias.» 56

Es un hecho que posee, tal como añade, un «interés filosófico". En mi opinión, Ortega lo asume con plenitud, bien sea como inspiración o como corroboración de su propia intelección. A nuestros efectos, mínima sería la diferencia. El resultado es que en su obra aparece similar tipo de ideas, con sus particulares consecuencias. Sirva como ejemplo un corto pasaje de su ensayo sobre Leibniz. En el mismo señala:

"Lo que la teoría física dice es trascendente a toda intuición y sólo admite representación analítica, algébrica." (IPL, VIII, 80)

Esta línea directriz de construcción simbólica transparece igualmente a lo largo de las páginas que Weyl dedica a la ciencia natural, centrándose en su mayor parte en la física. De su densidad y riqueza de contenido aquí apenas nos es dado poder espigar algunas aserciones, las suficientes para intentar mostrar de manera clara cómo constituye un aspecto nuclear que bien ha podido, así nos lo parece, transvasarse al orbe del pensamiento orteguiano. En una afirmación de matices gnoseológicos, sobre los que habremos de volver, el físico alemán manifiesta que hay una concesión de idealismo por parte de la ciencia, al reconocer ésta que

55 Op. cit., p. 73.

56 Op. cit., p. 73. 
«su realidad objetiva ha de ser construida... y que no puede construirse absolutamente pero sólo en relación a un sistema de coordenadas arbitrariamente supuesto y en meros símbolos" 57 .

Símbolos que, obviamente, son de carácter matemático. El mundo real, aquel que es el objeto del conocimiento, o sea «el mundo objetivo, representable sólo por símbolos" 58 , se halla relacionado con el mundo dado, lo que aquí sería tanto como decir con el material fenoménico proporcionado por nuestra experiencia, por medio de una "correspondencia, una transformación en sentido matemáticon 59 . El método básico que une a la matemática, muy particularmente en el caso de la geometría, con la física, es la "axiomática» que, según nos dice,

«se revela... como el modelo de un realismo purificado que postula un mundo trascendental pero se contenta con recrearlo en símbolosm 60 .

$\mathrm{Al}$ recapitular sobre la formación de teorías en la física moderna, destaca una vez más el vector temático al que venimos aludiendo. Los "materiales de construcción» de esta ciencia, en cuyo origen se hallan figuras de la talla de Copérnico, Kepler y Galileo, "no son ya — declara Weyl- los elementos de conciencia abstraídos de la realidad, sino símbolos puramente 'aritmséticos'» 61 . De Dilthey recoge la expresión de «la teoría de la construcción de la naturaleza por medio de elementos lógico-matemáticos de conciencia dados a priori, 62 . Y de un libro de Dingler, Die Grundlagen der Physik (p. 305, 1923), destaca la definición de la física como uese dominio científico en el cual se lleva hasta su fin el principio de construcción simbólica” ${ }^{63}$. Este género de manifestaciones acerca de la construcción simbólica, que vendría a ser el correlato teorético de una "realidad trascendente", mas no patente, poseen, a mi entender, el suficiente calado para cubrir el objetivo propuesto de mostrar una línea temática muy significativa que deseábamos destacar. La pura reiteración sobre este punto, en todo caso, parece innecesaria.

$\begin{array}{ll}57 & \text { Op. cit., p. } 132 . \\ 58 & \text { Op. cit., p. } 135 . \\ 59 & \text { Op. cit., p. } 134 . \\ 60 & \text { Op. cit., p. } 140 . \\ 61 & \text { Op. cit., p. } 171 . \\ 62 & \text { Op. cit., p. } 171 . \\ 63 & \text { Op. cit., p. } 171 .\end{array}$


La incidencia más clara y destacada de esta idea en la concepción que tenemos del Universo, en particular del estrato material de lo infinitamente pequeño, zona que estudia la ciencia física y que a tan inconmensurable distancia se halla del habitual mundo circundante, surgió de la teoría cuántica. Supuso una ruptura con los esquemas básicos que han operando en la mente humana. Todavía hoy, hay algunas implicaciones que, en lo esencial, tampoco hemos podido asimilar con plenitud. En el artículo de Weyl, escrito -como él mismo recuerda64_ en 1926, por tanto, un poco antes del surgimiento de la interpretación ortododoxa de la escuela de Copenhague, se recoge, no obstante, un aspecto decisivo. La nueva concepción cuántica renuncia a "cualquier clase de retrato espacial de los eventos atómicos» 65 , idea que volverá a reiterar páginas más adelante casi en los mismo términos, cuando nos dice que los resultados de la mecánica cuántica unos obliga a abandonar cualquier retrato espacio-temporal de los procesos atómicos" ${ }^{66}$. Apoyado en las palabras de Niels Bohr, opinión tomada de un artículo de 1926, Weyl nos transmite la convicción reinante entre los físicos acerca de que en la nueva física ha tenido lugar un cambio decisivo, pues se ha producido

"una falla esencial de las representaciones en espacio y tiempo sobre las cuales se ha basado hasta ahora la descripción de los fenómenos naturales» 67 .

Aunque todavía se estaba en el comienzo de un proceso de "desvanecimiento de la materia» y de otros conceptos tradicionales -eventos igualmente reflejados en la posterior obra de Ortega-, la exposición del artículo de Weyl es más que suficiente, en mi opinión, para dar cobertura científico-teórica a los desarrollos efectuados por el filósofo madrileño sobre este hilo conceptual de la ciencia como construcción simbblica. Incluso, en las limitadas referencias a las ciencias biológicas efectuadas por Weyl en las últimas páginas, cabe hallar explicación de una particularidad expresada en diversos textos del catedrático madrileño. La caracterización de la física como construcción simbólica la extiende también a la ciencia íntegra. No es extraño que las ciencias formales participen de consideración tal, mas no ocurre igual con otro conjunto de ciencias naturales - p. e., las biológicas-, en las cuales no eran preponderantes los méto-

\footnotetext{
64 Op. cit., p. 212.

65 Op. cit., p. 183.

66 Op. cit., p. 212; cfr. con ORTEGA (IPL,VIII, 78-81).

67 Op. cit., pp. 212-213.
} 
dos matemáticos y experimentales y cuyo referente quedaba sólidamente anclado en la realidad. Pues bien, una afirmación de Weyl al respecto nos parece muy reveladora como posible fuente de inspiración para la aludida extrapolación de Ortega. Dice así el matemático germano:

«No hay razón para ver por qué la construcción simbólica teórica deba detenerse frente a los hechos de la vida y de la psique." 68

La idea subyacente, como él mismo hace constar, apunta hacia "la unidad de la naturaleza" y su lógica consecuencia, «la unidad del método científico».

\section{Holismo}

En la concepción globalizante de la teoría de ciencia, de su noción como un bloque ideacional compacto, cuyas partes aisladas no admiten contrastación con la Realidad, hallamos referencias orteguianas asociándolo explícitamente con el físico que nos ocupa, incluso citando el pensador español el artículo de 1927 del científico alemán. En efecto, en un nota a pie de página de su texto sobre Hegel y la historiología nos refleja la opinión de Hermann Weyl sobre el género de correspondencia que se produce entre teoría y mundo real, en una versión en cierto modo similar a la conocida con posterioridad como tesis Duhem-Quine. Dicha correspondencia,

"no llega a consistir ni siquiera en un paralelismo, de suerte que "cada enumerado particular tenga un sentido verificable en la intuición". En la ciencia natural, "la verdad forma un sistema que sólo puede ser comprobado en su integridad". [...] En algún pequeño artículo Weyl formula más enérgicamente este diagnóstico, diciendo que el corpus de la física toca sólo con algunos de sus puntos el mundo de la experiencia, es decir, de los "hechos"”. (FHH, IV, 527, nota 2)

A la hora de analizar la estructura de toda ciencia que verse sobre realidades -la física se toma como caso paradigmático-, constatamos la opinión de Ortega, consistente en atribuir al componente experimental de ésta un rango en cierto modo inferior al del otro elemento, el de mayor importancia, que es la construcción teórica. El experimento queda reducido al papel de confirmación.

68 Op. cit., p. 243. 
Las ideas de la física asumen la característica de ser "autógenas y autónomas". No consisten, pues, en mero extracto o deducción del mundo fenoménico. Y no sólo esto, sino que para llegar a convertirse en verdades físicas será necesario recurrir a una consideración de orden global. El rasgo de holismo y la prefiguración de un simbolismo, más tarde desarrollado, quedan manifiestos en sus afirmaciones acerca de que las referidas ideas físicas sólo logran alcanzar ese status de verdad física

"cuando el sistema de ellas es comparado con un cierto sistema de observaciones. Entre ambos sistemas no existe apenas semejanza, pero debe haber correspondencia». (FHH, IV, 527)

En su obra La idea de principio en Leibniz y la evolución de la teoria deducti$v a$, escrita veinte años después, lo cual nos da ya el índice de la persistencia de esta concepción, vuelve Ortega a referirse a estos temas, tratándolos con una mayor amplitud, pero manteniendo, no obstante, el aspecto nuclear del asunto. Allí viene a reiterar ese extraño hecho de que la teoría física en modo alguno pretendía ya estar en "correspondencia similar" con la Realidad y que el desarrollo de la física contemporánea no hacía más que destacar. En estas páginas, y siguiendo el mismo rumbo, Ortega se manifiesta sobre que «Hermann Weyl da expresión gráfica» a la impactante situación, describiendo una figura -impresa en el libro-, reproducción, a su vez, de la dibujada en el libro de Weyl. Se trata de la representación de la "teoría física" por un semicírculo cuyo diámetro se ha sustituido por una línea ondulada. Colocada ésta sobre una línea recta -expresión de la Realidad-, sólo la toca en los puntos de máxima amplitud hacia el exterior, puntos que son los experimentos. Mas «el corpus interior de las proposiciones física” en ningún punto coincide con la Realidad. Para Ortega, transvasando la idea de Weyl referente a esta especial noción de correspondencia:

«No hay, pues, similaridad alguna. No hay correspondencia de identidad entre los contenidos o puntos interiores de la teoría y las partes de la Realidad". (IPL, VIII, 79-80)

$\mathrm{Y}$, a continuación, se pronuncia una vez más sobre la concepción holista de la teoría física, manifestando:

"Lo que hay que comparar con las partes de la Realidad, no son las partes de la teoría, sino el conjunto de esta. Su correspondencia está garantizada por los experimentos, no por la similaridad". (IPL, VIII, 80) 
Conviene subrayar un punto significativo. De forma implícita a veces, y en otras ocasiones plenamente explícita, las características de la física, como ciencia ejemplar, serán proyectadas por Ortega sobre el conjunto de la Ciencia íntegra.

Retornemos de nuevo al texto de Weyl, intentando mostrar aquellas manifestaciones del científico alemán que han podido servir de inspiración al filósofo madrileño. La función de las matemáticas, que es «estar al servicio de las ciencias naturales" ${ }^{69}$, le lleva a establecer una notable diferencia entre ambos géneros de ciencias. La exigencia intuicionista de Brouwer acerca de los asertos matemáticos, "que cada uno debe traer dentro de sí su propio significado intuitivamente comprensiblew, en su opinión, no es traspasable al ámbito de la ciencia física, pues "lo que se pone a prueba al confrontar la física teórica con la experiencia es el sistema como un todo" 70 . Esta taxativa afirmación, efectuada en la sección dedicada a la matemática, tiene su contrapartida en aquella otra cuyo objeto es la ciencia natural. En el interesante parágrafo 17, de título bien significativo, Sujeto y objeto (Las implicaciones cientificas de la epistemologia), puede verse reproducida la referida figura inserta por Ortega en su libro dedicado a Leibniz, si bien en el artículo de Weyl se halla acompañada de una representación de la parte teórica redundante, sin ningún contacto con lo real, por lo que, según el autor, «debe dejarse de lado»71.

Tratando acerca de La esencia del espacio y la aplicación de lo que denomina el método geométrico, o sea la introducción de las necesarias nociones geométricas a fin de dotarlo de una estructura — cuya esencia es ideal- que permita la representación del orbe de lo existente, reitera esta noción de holismo:

«Las proposiciones geométricas, por lo tanto, son determinaciones meramente ideales, y tomadas en aislamiento individual no tienen ningún significado verificable por medio de lo que es dado. Sólo aquí y allá la red de determinaciones ideales toca a la realidad experimentada, $y$ en estos puntos de contacto debe 'concordar'., 72

Ya hemos tenido ocasión de estudiar cual es el tipo de concordancia o correspondencia que se establece. $Y$, por supuesto, es necesario distinguir entre ese "espacio matemático", orbe puramente ideal, "cuyas leyes son consecuencia lo-
Op. cit., p. 68.
Op. cit., p. 68.
Op. cit., p. 134.
Op. cit., pp. 148-149. 
gica de axiomas arbitrarios", del «espacio físico", que es «el esquema ordenador de las cosas reales" y a título de lo cual debe entrar "como una componente integral en la construcción teórica del mundo» ${ }^{73}$. Un poco más adelante, el autor nos va a hacer patente todo ello. A esta posición holista se podría oponer cierta observación que aparece poco después, al hablar sobre el ya aludido problema de las relaciones entre un espacio puramente matemático, imaginario por tanto, y el espacio físico real. Según Weyl «las leyes individuales de la física, al igual que las de la geometría, admiten una prueba experimental si cada una se considera por sí misma» ${ }^{74}$. La contraposición a la teoría holista se desvanece al considerar que estas "leyes individuales" son, precisamente, esas "determinaciones ideales" donde contactan las fronteras de dos orbes tan diferentes como son las teorías y su correlato, el mundo de la realidad. Las leyes a que se refiere el físico-matemático vendrían a constituir los elementos exteriores, dirigidos hacia lo real, de la esfera íntegra de las proposiciones constitutivas del orbe teórico. Algo que concuerda con la metodología efectivamente aplicada en el desarrollo de la ciencia, donde la experimentación se lleva a cabo sobre leyes empíricas muy concretas de diferente rango. Mas esto mismo no puede hacerse con toda la red de relaciones, de todo orden, en que aquellas leyes contrastables se hallan inmersas. Sin detenernos en pormenores, cabe destacar sobre el tema las profusas discusiones habidas en la filosofía de la ciencia acerca de la dicotomía teórico-observacional, lo que en este momento nos puede dispensar de ulteriores referencias a esta particular faceta del asunto.

Mas aunque este gran físico aluda a que leyes individuales, tanto geométricas, como físicas, admitan prueba experimental consideradas por sí mismas, ciertamente, no deja de precisar que «una teoría constructiva sólo puede ponerse a prueba como un todos 75 . Es esta una idea que adquiere singular relieve en su exposición y sobre la que páginas más adelante vuelve a insistir, casi en forma lapidaria. Aludiendo al "carácter constructivo de las ciencias naturales", al que nos hemos referido con anterioridad, afirma:

"No se les puede adscribir un sentido intuitivamente verificable a las proposiciones científicas particulares, la verdad forma un sistema que sólo en su totalidad puede ponerse a prueba." 76 
Por tanto, ambos géneros de ciencias, formales y naturales, constituyen una gigantesca construcción, como no cesa en poner de relieve el pensador alemán a lo largo de la obra comentada. De ahí su conclusión:

«No se deber rechazar la posibilidad de que varias construcciones diferentes pueden ser adecuadas para explicar nuestras percepciones.»

De esta frase encontramos ecos en Ortega, cuando contestando a la pregunta sobre cómo sabemos que la física es correspondencia simbólica, responde:

"Porque son muchas las correspondencias igualmente posibles; como es posible, en las formas más diversas, la ordenación de cosas." (¿QF?, VII, 303)

En apoyo de su argumentación, Weyl -y en esto le sigue el pensador madrileño (¿QF?, VII, 303) -, trae a colación unas palabras pronunciadas por Einstein en 1918, en un discurso con motivo de sexagésimo aniversario de Max Planck 77 . Señalemos que, aun expresando la misma idea y como ocurre con otro texto que más adelante veremos, la versión que Ortega nos transmite, respecto de la traducción castellana de 1965 , posee una mayor contundencia a la hora de expresar similar noción.

\section{Indeterminismo}

La cuestión del indeterminismo, en el tratamiento orteguiano, queda estrechamente asociada a la introducción en la física de los métodos matemáticos estadísticos. Y aunque el tema reciba una atención reducida y nos quede ahora un tanto excéntrico, resulta importante por presentar una evidencia muy reveladora.

La visión que Ortega tiene acerca de la física no-clásica, en cuanto nuevo tipo de conocimiento, inasimilable al hasta entonces vigente, halla su soporte en dos eventos surgidos del propio desarrollo de ciencia física ${ }^{78}$. El primero de ellos consistía en el proceso, de progresión creciente, que, desde hacía varios lustros, había llegado a transformar la teoría física en «un sistema de leyes esta-

77 WEYL, op. cit., p. 174; ORTEGA: VII, 303.

78 Cfr. con la exposición realizada en (RH44, XII, 287); e (IPL, VIII, 76-77). 
dísticas». Y, en opinión de nuestro filósofo, proceso tal había venido a significar una degradación de la noción de verdad asociada a un principio de causalidad convertido en inoperante en la misma medida que se producía un "desvanecimiento de la materia». El carácter de verdad simple, indisolublemente asociado al ser real, se transforma en mera verdad probable, destilada de la probabilidad resultante de las leyes sustentadas en el cálculo estadístico. La conclusión de Ortega es que el conocimiento que la física proporciona no tiene ya como objeto el "Ser real» sino el «Ser probable», género de ente o cosa, afirma, todavía no "congruentemente definida». De este modo, la física no nos habla ya de la Realidad. El otro elemento que viene a complementar el nuevo y extraño carácter que presentaba el conocimiento físico, y del que aquí no vamos a ocuparnos, era el principio de indeterminación - con el aspecto ligado a la intervención del sujeto en la experiencia cognoscitiva-, configurado como la base de la nueva física cuántica.

En el texto de su curso universitario ¿Qué es filosofia? podemos encontrar un pasaje donde, con la finalidad de refutar una posible objeción sustentada en el determinismo, manifiesta lo siguiente, transcribiendo, con mención expresa, la idea expuesta por Weyl:

"Me permito hacer notar que la teoría determinista, así, sin más, hoy no existe ni en filosofia ni en física. Para apoyarme al paso en algo, a la vez, sólido y breve, oígase lo que dice uno de los mayores físicos actuales -el sucesor y ampliador de Einstein, Hermann Weyl-en un libro sobre lógica de la física publicado hace dos años y medio: "De todo lo dicho se desprende cuán lejos está hoy la física - con su contenido por mitad de leyes y de estadísticas-en posición de aventurarse a hacer la defensa del determinismo"." (¿QF?, VII, 432)

En la versión castellana que manejamos ${ }^{79}$, queda reflejado, evidentemente, el mismo concepto, si bien se limita a describir ese rasgo de la física expresando que «apenas puede pasar como defensora del determinismo".

En el libro del físico alemán, el tratamiento de este tema adquiere una mayor entidad, realizando una breve incursión de carácter histórico acerca del desenvolvimiento de la noción de probabilidad por parte de algunos pensadores de relieve. En estas líneas, sin embargo, sólo podemos recoger las ideas directa-

79 Cfr. op. cit., p. 239. 
mente relacionadas con las opiniones orteguianas. Así, con respecto a la física estadística - la que se halla en la base del proceso a que Ortega aludía-, Weyl afirma:

"Ahora es claro que la mayoría de los conceptos físicos, especialmente los que conciernen a la materia y su estructura atómica (por ejemplo, la densidad de un gas), no son exactos sino estadísticos, esto es, representan valores medios afectados por cierto grado de indeterminación.» 80

Como consecuencia, "la mayoría de las 'leyes' físicas usuales, especialmente las que conciernen a la materia», pierden la mantenida consideración de «leyes estrictamente válidas de la naturaleza", para asumir un aspecto de "regularidades estadísticas». Esta física estadística queda justificada en virtud "del hecho de que los complicados procesos moleculares no tienen relación directa con nuestras percepciones» 81 . Circunstancia que, ciertamente, tendrá una proyección aún mayor, si cabe, respecto de los hechos y relaciones objeto de la mecánica cuántica. En algunos otros pasajes sedimentan las conclusiones de Weyl que más inciden sobre el tema. Así, nos dice:

"De cualquier manera, en la realización de la investigación física, la estadística juega hoy una parte tan importante como la ley estricta.» 82

Para finalizar este apartado vamos a transcribir otro texto, que apunta ya a esa dualidad básica, apertura de la ruta hacia la conversión del ser real en ser probable, asumida por Ortega:

"De las dos leyes que son de importancia universal para todos los fenómenos físicos, la ley de conservación de energia y la ley del continuo crecimiento de la entropía, una es prototipo de ley estricta, la otra de ley estadística.) 83

\section{Métrica}

El tema de la medida es una de las vías que más directamente nos conducen al núcleo central de la tesis orteguiana sobre la ciencia. Y dentro de su radio de

\footnotetext{
80 Op. cit., p. 226.

81 Op. cit., p. 227.

82 Op. cit., p. 230.

83 Op. cit., p. 230.
} 
acción, convendría atender a la introducción de un aspecto muy importante. Desde su perspectiva, se ha operado un cambio radical en dicha empresa humana, habiendo dejado de ser la ciencia conocimiento. Para el catedrático madrileño, el conocimiento tiene un sentido que queda caracterizado como "presencia de la Realidad al pensamiento" (IPL, VIII, 77, 79 y 81 ), o como diría en otra ocasión, "penetración perfecta del objeto por el intelecto de su sujeto" (¿QF?, VII, 309) —otra forma de imbricar los mismos términos-, donde se aprecian resonancias que nos llegan del pensamiento clásico griego. Mas desvanecida la identificación de la ciencia contemporánea con lo que había sido considerado la esencia tradicional del conocimiento, fenómeno que él creía entrever en el perfil de su época, una actividad operativa asume el centro rector de la ciencia: la medición. En la visión orteguiana, la ciencia queda constreniida a un "mundo interior" del hombre. Mundo que, además, va permanecer casi obturado hacia la realidad exterior, con la que sólo comunica a través de la medi$\mathrm{da}$, que deviene sustituto del conocimiento de la cosas, del mundo, al menos en cuanto a su parte física o substrato principal se refiere. $Y$ con la extraordinaria calidad de su verbo, propia de uno de los mejores prosistas de nuestra lengua, expone así su idea directriz:

"Algo es real para la física cuando da ocasión a que se ejecuten ciertas operaciones de medida."

$\mathrm{Y}$ añade, en condensada enunciación donde refulge su idea sobre la nueva visión:

"Sustituye la realidad cósmica por el rito humano de la métrica.» (FHH, IV, 532)

Vemos, pues, que el núcleo funcional de la ciencia - refractada en la física- experimenta un desplazamiento, presente ya en los inicios del desarrollo de la física moderna. Es Galileo quien, como el filósofo madrileño subraya, "define maravillosamente la nueva ciencia que entre las manos le nace» (VC, IV, 65). Tal como Ortega hace constar, el iniciador de la física moderna define esta ciencia con las siguientes palabras:

"Consiste - dice- en medir todo lo que se puede medir y en conseguir que pueda medirse lo que no se puede medir. (Ejemplo de esto último, el calor. La fisica del calor consiste en inventar el termómetro).» (VC, IV, 65)

Concepto que hallamos reiterado en su libro sobre Leibniz: 
"Medir todo lo que se puede medir y hacer que se pueda medir lo que no se puede medir directamente" (IPL, VIII, 75)

Como nuestro principal empeño se ciñe a intentar poner de relieve lo que el artículo de Weyl ha podido significar para nuestro filósofo, nos vamos a limitar, en este punto, a transcribir el parecer del matemático al respecto. Dice éste:

"La opinión de que en el mundo real las conexiones cognoscitivas sólo pueden encontrarse si las determinaciones cualitativas se reducen a cuantitativas, que en tiempos modernos se ha refinado en oposición a la filosofía de Aristóteles, ha asumido importancia fundamental para las ciencias naturales.» 84

Y unas líneas más adelante expresa la concepción galileana. Sus palabras son harto significativas para el hilo de nuestra exposición, a tenor de la similitud con las manifestaciones de Ortega, a las que acabamos de hacer mención. Weyl lo expone de siguiente manera:

"Galileo enuncia el principio, "medir lo que es medible y tratar de hacer medible lo que todavía no lo es". Su invención del termómetro es una ilustración espléndida a la segunda parte de este postulado.» 85

\section{Gnoseología}

$\mathrm{Al}$ abordar los aspectos gnoseológicos en los que el científico germano incide, entramos en la recta final de nuestro recorrido. Lo primero, y tal vez más importante, que es menester aclarar es que se trata de una línea temática a la que no cabe hallar una repercusión explícita en los textos orteguianos. Incluso, cabe decir que, de existir, ha quedado fundida en el crisol de su pensamiento. Su empeño, en cuanto dirigido hacia el núcleo fundamental de la metafísica, que atañe a los problemas del ser y del conocer, se halla orientado según una dirección que le es propia. Su trayectoria filosófica tenía como foco la tesis metafísica de la coexistencia, inseparable y dependiente, del yo con las cosas, habiendo cristalizado, hacia 1916, en la imagen metafórica de los Dii consentes. En 
comprimida expresión, que pretende superar las tesis realista e idealista de la tradición filosófica, Ortega afirma:

"Yo digo: mundo independiente, pensamiento independiente, no existen. Son dos meras hipótesis, dos construcciones teóricas, no la realidad." (RH40, XII, 181)

Idea central, expresada también en la conocida formulación «yo soy yo y $\mathrm{mi}$ circunstancia", que configura la filosofía orteguiana en torno a la concepción de la vida como realidad radical. La mencionada superación onto-epistemológica, conservando ambas tesis, pretende atribuir a cada una de ellas la parte de razón que le asiste. Bajo este prisma, parece adecuado mostrar las manifestaciones de Weyl, poniendo de relieve la asunción por parte de la ciencia, tanto de supuestos realistas como idealistas. A sus ojos, las dos posiciones se presentan como complementarias, sin sentido excluyente, lo cual no deja de ser un primer paso hacia una superación que en Weyl no se halla formulada de forma explícita. Aunque, a tenor de los ejemplos aducidos sobre la interacción entre sujeto y objeto, cabe también afirmar que se halla prefigurada.

Veamos, en primer término, las tres direcciones gnoseológicas básicas que, en opinión del físico-matemático, se habían hecho patentes, por aquel tiempo, en las investigaciones acerca de los fundamentos de las matemáticas. El realismo ingenuo correspondía a una teoría conjuntista "que no se da cuenta de la transición de lo dado a lo trascendente". El creador del intuicionismo, Brouwer, encarna «el idealismo, al pedir que toda verdad se reduzca a lo intuitivamente determinado" ${ }^{86}$. Es el formalismo axiomático, centrado en torno a la figura de Hilbert, un tercera vía, donde

"la conciencia hace el intento de 'saltar sobre su propia sombra', dejar atrás lo dado y representar lo trascendente - pero, ¿cómo hubiese podido ser de otra forma?, sólo a través del simbolon 87 .

Noción esta última transferida al campo de la física, ciencia de realidades, donde, de igual forma, posee aplicación en virtud de las transformaciones ope-

86 Convendría matizar que Brouwer quizá representaría más adecuadamente esa posición por pedir en cada caso una construcción determinada. Las reiteradas ocasiones en que por parte de Ortega se aduce el caso de Brouwer no parece compaginarse excesivamente bien con este carácter de idealismo que Weyl le atribuye, habida cuenta del explicitado desideratum orteguiano de superar esa posición, centro cordial de una Modernidad a ]a que consideraba caducada.

87 Op. cit., p. 73. 
radas en su órbita por obra de un prodigioso desarrollo. Será un progreso que, paradójicamente, desembocará en un "desvanecimiento» de su objeto tradicional. Así pues, si de las matemáticas pasamos a las ciencias naturales, que estudian la realidad, podemos encontrar también consideraciones que no carecen de interés para el hilvanado de nuestra trama. Las apariencias subjetivas en que la realidad cósmica se nos presenta de modo fenoménico, p. e., deben quedar explicadas por un "estado objetivo de cosas" que es su correlato:

"No existe una diferencia en nuestras experiencias a la que no corresponda una diferencia en la situación objetiva (una diferencia, además, que es invariante bajo transformaciones arbitrarias de coordenadas)... 88

Cabe destacar la alusión al sistema de coordenadas, pues asume un interesante carácter, como después vamos a ver. En dicha experiencia queda incluido, igualmente, el "cuerpo del ego como un objeto físicon, lo que equivale a reconocer ese carácter dual, a la postre aporético, del papel que juega el sujeto humano en la constitución del mundo. En opinión de Weyl, «la experiencia inmediata es subjetiva y absolutco. El orbe cotidiano en el que «las ciencias naturales tratan de cristalizar", utilizando métodos que no son otra cosa sino depurado desarrollo de los mismos criterios utilizados para «experimentar la realidad en nuestra actitud natural diarian, deviene en esa experiencia un mundo objetivo, que «es por necesidad relativon. Mundo que

«puede representarse por medio de cosas definidas (números y otros símbolos) sólo después de haber introducido en el universo un sistema arbitrario de coordenadas".

La conclusión que de ello extrae es que, a su parecer

«este par de opuestos, subjetivo-absoluto y objetivo-relativo, contiene una de las ideas epistemológicas más fundamentales que pueden colectarse de la ciencia” 89 .

Retornando a la línea de convergencia epistémica antes mencionada, subrayemos ahora esa complementariedad de realismo e idealismo, presente en el ámbito de las ciencias naturales, $y$ en la que acaso cabría ver el germen, aun en forma harto vaga, de la caracterización orteguiana de la física como conjunción

88 Op. cit., p. 131.

89 Op. cit., p. 131. 
de construcción teorética y verificación experimental. La noción de complementariedad, bajo otra óptica, pronto se convertiría en eje interpretativo de los estratos de realidad para los cuales posee validez la nueva teoría cuántica. Una y otra concepciones gnoseológicas - aunque sólo en aspectos parciales- subsisten en dichas ciencias, operando de forma conjunta, y, al parecer, sin interferencias invalidantes. Como Weyl nos dice:

«Dentro de las ciencias naturales las filosofias conflictivas de idealismo y realismo significan principios de métodos que no se contradicen entre sí.»90

En la ciencia habría, pues, una faceta realista. El mundo objetivo construido por aquélla debe explicar los datos presentados por los sentidos. Aquí opera un principio que considera fundamental (cfr. cita núm.) y que resalta con una expresión de Helmholtz: "Una diferencia en las percepciones que se nos ofrecen está siempre basada en la diferencia en las condiciones reales». Al sujetarse a dicho principio, nos dice, "las ciencias naturales proceden realísticamente" 91 . De esto se infiere que

«Una diferencia que de ninguna manera se puede hacer patente a nuestra percepción es inexistente. Esto tiene gran importancia como principio metódico de la construcción teórica." 92

Lo anterior consolida un firme anclaje en la realidad, pues viene a corroborar el principio general de que los fenómenos no son meras apariencias, imágenes fantasmagóricas de una realidad virtual engendrada por la mente del sujeto. Por el contrario, dichos fenómenos presentan la superficie de una realidad que el sujeto no construye, y esto al margen de que al sujeto cognoscente le sea posible, o no, alcanzar el auténtico fondo, el en sí de las cosas conocidas fenoménicamente.

Mas, por otra parte, el conocimiento surgido de la ciencia también contiene aspectos de idealismo. Desde el punto de vista filosófico y desde el científi-

90 Como sabemos, en este punto Ortega habia ido mucho más lejos. Lo que aquí es una especie de coexistencia metodológica, la había transformado el pensador de El Escorial, bien que en el nivel filosófico - más radical, por lo cual también debe explicar las operaciones de carácter generalizador de la ciencia-, en una concepción superadora de ambas posiciones. Superación en un nivel más alto, donde, si bien absorbidas, igualmente quedan conservadas.

91 Op. cit., p. 131.

92 Op. cit., p. 133. 
co, se sostiene la subjetividad de las cualidades sensoriales. Como fundamento del idealismo epistemologico, se reconoce que

«queda manifiestamente incomprensible cómo una calidad separada de consciencia puede atribuirse como una propiedad tal a una cosa tal» 93 .

Y, bajo diferente ángulo, se afirma que las cualidades "con que se visten para mí los objetos" no dependen sólo de ellos, aduciéndose sobre todo, «las circunstancias físicas concomitantes" y la "propia organización psicofísica» del sujeto. Veamos la conclusión en un pasaje, donde su pensamiento se decanta:

«Por otro lado la ciencia le concede al idealismo que su realidad objetiva no está dada sino que ha de ser construida..., y que no puede construirse absolutamente pero sólo en relación a un sistema de coordenadas arbitrariamente supuesto y en meros símbolos." 94

Problema sin resolver es si la referida construcción simbólica, por la que la ciencia produce el mundo objetivo, constituye una tercera vía gnoseológica, superadora tanto del realismo como del idealismo. Las conclusiones que cabe extraer no parecen ser concluyentes respecto a una alternativa real. Mas si esta cuestión no obtiene una explícita respuesta, en cambio, al proponernos ciertos modelos explicativos, tenemos la impresión de hallarla implícita, pues en ellos transparece una imagen ideal que resulta útil, en nuestra opinión, a la hora de comprender mejor la noción orteguiana de una realidad radical consistente en la implicación mutua de yo y mundo, de sujeto y objeto. Nos vamos a limitar a un solo ejemplar, característico, sin embargo, de cómo la ciencia arrojaba luz sobre problemas propios de otros orbes del pensamiento. Weyl manifiesta:

"Con respecto al problema de realismo contra idealismo encontramos una analogía sorprendente en geometría, que tiene con él una conexión real en tanto que en el mundo objetivo el sistema de coordenadas es, como si fuese, el residuo de la aniquilación del ego.n 95

Tomando un ejemplo de un parágrafo anterior, nos propone considerar vectores $x$ en un plano, cuya representación numérica o coordenadas es función de una determinada base, consistente en dos vectores linealmente independientes.

\footnotetext{
93 Op. cit., p. 125.

94 Op. cit., p. 132.

95 Op. cit., p. 138.
} 
Para simplificar, pues no deseamos entrar en más detalladas consideraciones, vemos que Weyl interpreta a los vectores $x$ del plano como «análogos de los objetos en el mundo real"; a las bases, que pueden ser infinitas, como «análogos de observadores reales»; y a los números que expresan las coordenadas como «análogos de los fenómenos subjetivos». En esta especie de modelo, las coordenadas asumen, así, "'la apariencia del objeto $x$ para el observador [base vectorial]". Obviando la exposición sobre posibles operaciones algebraicas, sólo señalaremos que, según el autor, «coordenadas absolutas de un vector son sus coordenadas relativas con respecto a la base absolutar. Y esta base absoluta no es sino una asignación que efectuamos a cualquier base que elegimos de forma arbitraria. La analogía sugerida por el físico alemán,

«supone que sólo está abierto a nuestra intuición el dominio de los números (las apariencias) y no el espacio geométrico (las cosas mismas). Por tanto el modelo es el mundo de mis fenómenos y la base absoluta es ese observador distinguido 'yo' que asegura que todos los fenómenos son como él los ve: en este nivel, objeto, observador y apariencia pertenecen todos al mismo mundo de fenómenos, ligados por relaciones entre las que podemos distinguir las 'objetivas' o invariantes. Observador real y objeto real, yo, tú, y el mundo externo surgen, por decirlo así, al unísono y en correlación unos con otros al sujetar a la esfera de 'apariencias algebraicas' al punto de vista de la invarianciam. 96

Y después continúa en línea fenomenologizante, afirmando que la analogía así dispuesta proporciona un "hecho inmediatamente inteligible»:

"el único 'yo' de conciencia pura, la fuente de todo significado, aparece bajo el punto de vista de la objetividad como un solo sujeto entre varios de su tipon 97.

Pero adecuarse a la realidad significa dar otro paso más, pues no estamos aquí ante el sujeto transcendental kantiano, sino que se trata de un sujeto que es, como Ortega diría, «el yo que es cada cual». De ahí que prosiga afinando su análisis acerca del "sujeto absoluto", del yo que, no obstante, "permanece único para siempre, a pesar de la equivalencia objetiva de los diversos sujetos" 98 . La noción que de esto se deriva, es decir, el intercambio posible de sujetos, de- 
bido a su equivalencia, fundamentado en la premisa de que «Tú eres para ti una vez más lo que yo soy para mí, portador consciente-existente del mundo de los fenómenos" 99 , sólo le parece posible, en el paradigma propuesto, si se salta desde el modelo algebraico de la geometría vectorial afín al modelo axiomático, en cuyo contexto una pareja de vectores-base, análogo del observador, «sólo puede distinguirse por medio de un acto de exhibición individual. Lo cual equivale a que el término 'yo' se convierta en "pauta y fuente de todos estos actos demostrativos". He aquí cómo, siguiendo esta línea analógica, se vuelve al mismo nódulo central de la concepción de Weyl, en cuyo foco se halla el formalismo axiomático. Estas ideas, recogidas por mi parte de forma tan condensada, le conducen a la conclusión -ya mencionada con anterioridad (cfr. nota núm.) - de que en la axiomática cabe contemplar «el modelo de un realismo purificado" que trasluce un mundo trascendental, mas recreado en símbolos.

Resta por destacar una idea que, si bien ya reseñada, vista bajo otro ángulo brilla con luz propia y de cuya importancia vamos a ver la razón. Se trata del énfasis proyectado sobre el sistema coordenado para el conocimiento del mundo real. En cierto sentido, el establecimiento de bases coordenadas no es sino el análogo de la introducción del sujeto y significa la apología de su papel en el proceso cognoscitivo y aun de constitución del mundo, como el siguiente texto nos mostrará:

"La medición de hechos físicos observables (que no son cantidades escalares sino vectoriales o 'tensoriales', tales como el campo métrico) sólo es posible en relación a un sistema coordenado introducido arbitrariamente en el universo. Esta libre inserción de coordenadas y la medición basada en la adición de elementos iguales puede ser típica para los diferentes niveles en que se aplican los métodos: el primero a la forma, el segundo al contenido del universo.» 100

Mas, como añade, es la representación simbólica, a lo que parece, "la única modalidad decisiva de todas las mediciones». Aun los números, como nos indica, no son los únicos símbolos que se pueden utilizar para ello. Y en frase que lo sintetiza, afirma:

"La medición permite una presentación conceptual de las cosas (relativas a la supuesta base de medida), por medio de símbolos." 101 
Como se nos hace patente por medio de este modelo propuesto por Weyl, la cuestión de la medida adquiere una singular relevancia en orden a la relación indisoluble sujeto-objeto, donde el mundo objetivo queda constituido. De ahí que deseemos cerrar este tema con un texto orteguiano — del año 1929- que, a la vista de lo anterior, adquiere pleno significado. Reivindicando la históricamente desvalorizada sentencia de Protágoras, del hombre como medida de todas las cosas, afirma el filósofo madrileño que las cosas, en cuanto ellas mismas, «no tienen medida, son desmesuradas, no son más ni menos, ni así, ni del otro modo, en suma ni son ni no son. La medida de las cosas, su modo, su ni más ni menos, su así y no de la otra manera, es su ser y este implica la intervención del hombre». (AK, IV, 58)

Hemos llegado al término de nuestro recorrido. Esperamos que el amable lector que nos haya acompañado pueda compartir la opinión vertida en estas páginas, acerca de la auténtica dimensión que adquiere esa influencia o inspiración proyectada sobre el pensamiento orteguiano y que ha sido nuestro propósito mostrar.

\section{Nota bibliográfica}

Salvo mención expresa, procederemos en la forma habitual de hacer referencia a los textos de Ortega, indicando el tomo de las Obras completas en números romanos y las páginas en cifras arábigas, siendo precedidos por una sigla identificativa del libro, ensayo, o artículo, a tenor de la siguiente relación:

\section{El tema de nuestro tiempo, 1923: TNT.}

«El sentido histórico de la teoría de Einstein» (Apéndice de TNT): SHE. Las Atlántidas, 1924: A.

"La resurrección de la mónada», 1925: RrM.

La rebelión de las masas, 1926-1928: RM.

"La Filosofia de la Historia de Hegel y la historiologían, 1928: FHH.

«Filosofía pura (Anejo a mi folleto Kant), 1929: AK.

¿Qué es filosofia? ¿QF?

"Vicisitudes en las ciencias", 1930: VC.

«Prólogo para alemanes», 1934: PPA. 
Historia como sistema, 1935: HS.

"Bronca en la física", 1937: BF.

"La razón histórica», Buenos Aires, 1940: RH40.

"La razón histórica», Lisboa, 1944: RH44.

"Prólogo a Introducción a las ciencias del Espiritu, por Wilhelm Dilthey", redactado en 1946: PWD.

La idea de principio en Leibniz, 1947: IPL. 